\title{
TELEAUDIÊNCIA: PREMISSAS PARA UMA PEDAGOGIA ${ }^{1}$
}

\section{Proposta pedagógica orienta o desenvolvimento cognoscitivo do telespectador infantil e prepara-o para uma relação mais produtiva e crítica com a TV}

O protagonismo crescente da televisão na vida cotidiana das sociedades contemporâneas e a concomitante interação diferenciada que com ela desenvolvem os telespectadores apresentam uma série de desafios cognoscitivos e pedagógicos, tanto para os próprios telespectadores quanto para os investigadores e comunicadores preocupados em explorar, entender e, se for o caso, intervir nos processos de ver televisão.

Um destes desafios é, justamente, o tipo de conhecimento que se requer para interagir com a TV de maneira produtiva: uma maneira que possibilite aos telespectadores um encontro múltiplo, cada vez mais livre, autônomo, expressivo e, eventualmente, mais crítico.

Um conhecimento com estas características supõe, pelo menos, assumir que a relação entre TV e telespectadores é uma interação múl-

\section{O AUTOR}

\section{Guillermo Orozco-Gómez}

Professor Investigador do Departamento de Estudos da Comunicação Social, Universidade de Guadalajara, México. tipla, que envolve a existência da TV em suas três dimensões: meio, linguagem e instituição social. Envolve, igualmente, o telespectador como um sujeito cognoscente, ativo, mental, física e emocionalmente, frente à TV, e situado, de maneira particular, numa cultura, num contexto histórico específico e num estágio de desenvolvimento pessoal determinado.

Um dos grupos de telespectadores mais assíduo e, às vezes, mais vulnerável, porém permeável a uma educação televisiva diante da TV, é o constituído pelas crianças.

Com relação a isso, a investigação internacional sobre a vinculação das crianças com a TV deu resultados similares, que comprovam, por exemplo, que a maioria das crianças, em todos os países, passa mais horas frente à TV que diante do professor na sala de aula; que ver TV é sua atividade principal durante as horas em que se está em casa e que a TV exerce uma influência que, embora seja diferenciada, é importante no seu desenvolvimento cognoscitivo, afetivo, axiológico e simbólico ${ }^{2}$. 
Considerando o que ficou dito, quero apresentar, sinteticamente, uma proposta de ntervenção pedagógica que procura gerar um zonhecimento pertinente, relativo às crianças enquanto telespectadores, e a seus educadores enquanto orientadores do desenvolvimento zognoscitivo dessas crianças, a fim de que elas se descubram como tais, nos seus processos te ver televisão.

\section{UMA PEDAGOGIA DA TELEAUDIÊNCIA}

Uma pedagogia da televidência (ou seja, uma pedagogia que oriente o desenvolvimento zognoscitivo do telespectador infantil) distingue-se de uma pedagogia da TV, ou da comunização, na medida em que a primeira é centrada em conhecer os diversos aspectos do meio televisivo, enquanto a segunda privilegia os prozessos comunicativos em geral, cujo objeto de zonhecimento é justamente a relação dos telespectadores com distintos aspectos técnicos, lingüísticos, institucionais, formais e de conteúdo do meio televisão. Esta relação - TV/ telespectador - inclui, evidentemente, um conhecimento progressivo da TV e até mesmo do processo comunicativo, porém este é um conhecimento gerado e apropriado a partir do próprio telespectador, através da associação dos diversos elementos constitutivos de sua vinculação com a TV e da percepção que, sobre a própria $\mathrm{TV}$, ele venha a ter. Isso significa que o entendimento dos diferentes aspectos envolvidos na teleaudiência não se realiza por si mesmo, mas sempre em relação a cada um dos telespectadores. A partir dessa relação, gera-se um avanço progressivo que transcende a pura enunciação de características ou noções, avanço que leva à compreensão cada vez mais complexa - no sentido de Edgar Morin - com o objetivo último de possibilitar uma recolocação do mesmo telespectador frente à TV.

Parto do reconhecimento de que não se nasce telespectador, mas sim que o telespectador e a teleaudiência, enquanto ente coletivo, vão se conformando a partir das suas experiências concretas de interação com a TV e de outras instituições socializadoras, as quais intervêm nessas experiências.

A perspectiva pedagógica que proponho engloba algumas premissas. A primeira delas é a que diz que entre os telespectadores e a TV existem muitas coisas implícitas e muitos silêncios. Como pode ser observado, por exemplo, no caso da construção das notícias, enviezadas ou descontextualizadas por parte da empresa televisiva. Ou vistas de um determinado lugar ou não-lugar por parte dos telespectadores, os quais não lhes permite perceber ou perceber apenas parcialmente ${ }^{3}$ estes implícitos e estes silêncios, que nem sempre são obra da casualidade. São atributos da própria imagem televisiva que, enquanto mostra, também esconde, geralmente de acordo com um projeto político ou econômico e dentro de um contexto sociocultural determinado. Portanto, faz-se necessário, como ponto de partida, tornar evidente o que não é evidente, para aspirar a formar melhores espectadores de TV.

A segunda premissa diz que tornar evidente o que não seria é, ao mesmo tempo, uma condição e um objetivo da aprendizagem dos telespectadores, uma vez que evidenciar não é uma resultante automática da ação pedagógica, 
mas sim o produto de um processo de análise e de reflexão, através do qual os telespectadores vão se reconhecendo como tais e construindo um conhecimento sobre a TV, sobre si mesmos em sua relação com ela e sobre sua específica relação com a $\mathrm{TV}^{4}$.

A terceira premissa desta pedagogia de teleaudiência indica que uma estratégia adequada para obter o evidenciamento televisivo é o jogo ${ }^{5}$. A estratégia do jogo exercita a reação ao desafio, motiva a criatividade dos jogadores e facilita o ensaio de ações e a sua análise em função da pertinência para alcançar o objetivo. Essa postura é essencial para um pensamento analítico e potencialmente autônomo.

Outra das premissas resulta em que, com a implementação do jogo como um exercício analítico-lúdico, possibilita-se aos jogadores analisar seu próprio jogo. Isto vale como parte do esforço cognoscitivo para tornar evidente o objeto do jogo, o que constitui, ao mesmo tempo, um processo de pesquisa participante ${ }^{6}$. Assim, o que se vai tornando evidente consegue-se pela ação mesma do jogador e não pela ação única dos outros. O jogador, ao estar envolvido no processo, vai tornando possível o descobrimento daquilo que não é manifesto.

Outra premissa da pedagogia da teleaudiência - na linha de Paulo Freire ${ }^{7}$ diz que aquilo que deve ser estimulado durante o jogo é a curiosidade, por meio de um processo baseado em perguntas e não em respostas, o que constitui a essência de uma pedagogia problematizadora.
Ainda uma outra premissa diz que a aprendizagem se concebe como um processo integral, o que envolve diferentes âmbitos cognoscitivos. Mas é um processo sempre contextualizado de maneira específica, cuja característica principal é facilitar associações - conforme a técnica usada na psicanálise que permitam aprofundar conhecimentos sobre o objeto de análise, revelando seus implícitos e suas conexões mais profundas.

A perspectiva de intervenção pedagógica que aqui se propõe pode ser realizada combinando-se três tipos de exercícios lúdicos: brincar com a TV, brincar de TV e brincar a partir da TV.

\section{BRINCAR COM A TV}

Neste exercício, a meta é tornar evidente aos telespectadores infantis as propriedades lingüístico-formais da TV enquanto meio específico de comunicação. Este exercício envolve o princípio da complementaridade das linguagens auditiva e visual, como componentes inseparáveis e distintivos da linguagem televisiva. O exercício também envolve o princípio da polissemia, intrínseco a toda linguagem audiovisual, pelo qual o que se comunica nunca é unívoco, mas sempre suscetível de interpretações diversas e mesmo contraditórias ${ }^{8}$.

$\mathrm{O}$ aprendizado do primeiro princípio assume-se como condição do segundo. Este exercício requer a disponibilidade de um aparelho de televisão para o jogo e se desenvolve da seguinte maneira: primeiro,

4. KAPLUN, M. Ni impuesta, ni amada, la recepción televisiva y sus tierras incógnitas. (Nem imposta, nem amada, a recepção televisiva e suas terras incógnitas.) In: OROZCO, G (Coord): Miradas latinoamericanas a la televisión. (Olhar latino-americano sobre a televisão.) Proiicom. Universidad Iberoamericana, México, 1996. p. 67-89.

5. CORONA, S. Televisión y juego infantil. (Televisão e jogo infantil.) Universidad Autónoma Metropolitana, Xochimilco, México, 1987.

6. OROZCO, G. Hacia una pedagogia de la televidencia. (Por uma pedagogia da teleaudiência.) Comunicación y Sociedad (Comunicação e Sociedade.) Universidad de Guadalajara, México, n. 32, 1998. Ler sobre a dinâmica do jogo VIEIRA, Alice. Autonomia no jogo da leitura. Comunicação \& Educação. São Paulo: CCA-ECA-USP/Moderna, n. 4, set./dez. 1995. p. 31-34.

7. FREIRE, P. Pedagogia do oprimido. 9.ed., Rio de Janeiro: Paz e Terra, 1981.

8. FISKE, J. Television culture. (Cultura da televisão.) New York: Methuen, 1994. 
pede-se às crianças que se dividam em dois grupos. O primeiro grupo situa-se frente ao aparelho de televisão e o outro por trás. Ligase o aparelho em qualquer canal e em qualquer programa e se mantém essa situação por cerca de sete minutos. As crianças que estão por detrás do aparelho só poderão ouvir a transmissão, mas não verão a tela. Os que estão diante do aparelho escutam e vêem o que aparece na tela. Depois de decorrido o tempo estabelecido, desliga-se o aparelho e pede-se às crianças que só ouviram, que descrevam o que lhes parece que tenha sido mostrado na tela. As crianças que viram e ouviram julgarão a adequação das narrativas das outras crianças. O esforço analítico terá de centrar-se na comparação das narrativas com o que realmente apareceu na tela. Surgirão, necessariamente, diversas discrepâncias entre a versão narrada pelas crianças que somente ouviram e a versão sustentada pelas demais crianças.

Depois de comparar e distinguir as diferenças e, se for o caso, as semelhanças entre as duas versões, as crianças entenderão o que se requer, de ambas as linguagens, para uma teleaudiência. A linguagem televisiva não é uma simples súmula de uma e outra linguagem, mas sim uma fusão do auditivo e do visual.

Para reforçar esta descoberta pede-se então a todas as crianças que fiquem de frente para o aparelho de televisão e vejam a imagem, não podendo ouvir. Após alguns minutos com este exercício, desliga-se novamente o aparelho e se pergunta às crianças sobre $o$ que se passava na tela. Surgirão diversas versões, já que necessariamente cada criança terá que preencher com a sua imaginação ou senso comum o que não pôde ouvir. Isto dará possibilidade para diferentes interpretações. O papel do orientador será o de confrontar as crianças com a origem ou fonte de onde inferiram aquilo que não puderam ouvir. Algumas versões terão sua origem nas próprias imagens e movimentos vistos na tela ou na sequiência de cenas mostradas. Porém outras interpretações terão sua origem nas experiências anteriores das crianças com situações similares (ou que parecerem similares) às vistas na TV.

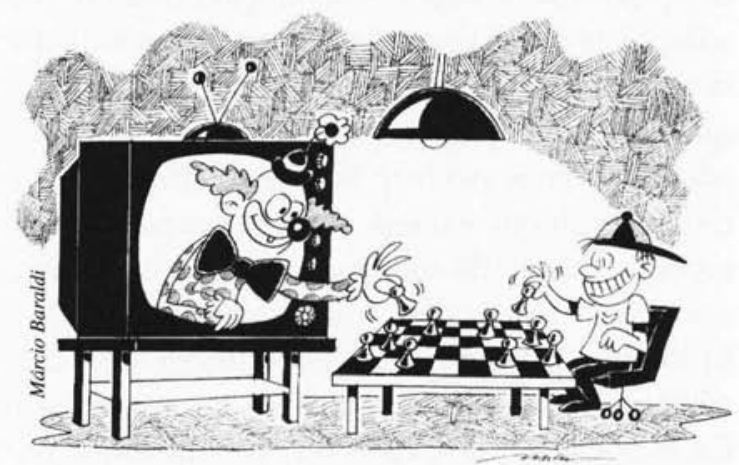

\section{BRINCAR DE TV}

Este exercício tem o objetivo de tornar claro para os telespectadores o princípio da representação televisiva. Concretamente, procura-se fazer com que as crianças, brincando, por exemplo, de cameraman percebam por si mesmas que aquilo que vêem na tela não é a realidade, mas sim uma sua representação.

O exercício se desenvolve da seguinte maneira: pede-se às crianças que tomem uma folha de papel e a enrolem até que ela fique em forma de cilindro, ou tubo; isto seria a lente de uma câmera de TV. Em seguida, pede-se às crianças que olhem através do tubo, usando um olho só. Cada criança deverá enfocar primeiro um objeto, à sua escolha, que esteja situado à sua direita, e depois outro que esteja à esquerda. Em seguida, pede-se às crianças que desenrolem a folha de papel e transformem a folha-lente numa tela de TV, na qual, rapidamente, desenharão os dois objetos enfocados. 
As crianças mostrarão, depois, suas telas com os objetos enfocados.

Necessariamente, os objetos estarão juntos, o que não corresponderá à realidade. $\mathrm{O}$ orientador deverá, a essa altura, perguntar o motivo da discrepância entre a situação dos objetos na realidade e a que aparece no desenho, na folha de papel. As crianças começarão a dar respostas e progressivamente chegarão a descobrir que a diferença se deve ao fato de que foi a lente que passou sobre a realidade, $\mathrm{e}$ não vice-versa. Ao fazê-lo, a lente fez, de início, um enfoque excludente, e depois uma integração técnica de ambos os objetos enfocados numa nova situação. Este entendimento possibilita a compreensão do papel mediador da câmera, pelo qual, mesmo sem intencionalidade ideológica explícita, a realidade é distorcida pela tecnologia televisiva. Com base neste exercício, pode-se continuar e passar a outro, com o objetivo de explorar e compreender como funciona, na prática, não só a representação televisiva da realidade como a sua manipulação ideológica.

Para fazer essa exploração, pede-se às crianças que prestem atenção a uma determinada situação e que movimentem a sua lente para captar, dessa situação, os elementos que lhes pareçam pertinentes. Pode-se encenar uma situação qualquer da vida real, um acidente, por exemplo, ou um trecho da aula de um dos professores. As crianças, ao presenciar tal situação, focalizarão os elementos que preferirem. Depois, desenharão na sua folha-tela os elementos focalizados e explicarão aos companheiros o que foi que captaram, por que o fizeram e por que o fizeram de tal maneira. $\mathrm{O}$ orientador ajudará a comparar as diferentes representações realizadas pelas crianças, a fim de que se torne evidente o papel da intencionalidade ou perspectiva sob a qual se realizou a representação.
O conhecimento que se produz com esses exercícios possibilitará verificar que tudo o que a TV mostra é uma representação, portanto uma construção, resultante da própria tecnologia televisiva e, além do mais, uma fabricação que pode ser manipulada de acordo com as intencionalidades específicas dos produtores da programação televisiva.

\section{BRINCARA PARTIR DATV}

O objetivo deste exercício é duplo. Por um lado, procura-se tornar evidente aos participantes o tipo particular de oferta televisiva que está ao seu alcance, por outro, suas próprias preferências e os motivos delas. A TV é assumida, neste exercício, na sua dimensão institucional. Pretende-se que as crianças explorem e compreendam as características da oferta de programação existente e sua vinculação específica com parte dela, que é o que constitui o particular referente de sua teleaudiência. O princípio envolvido neste jogo é o da classificação programática.

Para a realização deste exercício é preciso que se tenha à mão a programação de televisão do dia. O exercício se desenvolve da seguinte maneira: primeiro, pede-se às crianças que observem a lista de programas do dia e que anotem as suas dúvidas, para posterior esclarecimento. Depois, cada criança passará a colorir o espaço onde se encontram os títulos dos seus programas favoritos. Depois, em outra folha de papel, faz-se uma relação de todos os programas que foram coloridos, que são aqueles que, regularmente, a criança vê. $\mathrm{O}$ orientador ajudará as crianças a associarem cada programa, inicialmente, com um dos canais de TV, a fim de que se defina qual é o canal mais visto por cada um e por todos. Depois, as crianças, com a ajuda do orientador, 
classificarão os seus programas favoritos por gêneros programáticos, para descobrir que gênero mais vêem (por exemplo, telenovelas, desenhos animados, aventuras, concursos etc.). Depois, farão a comparação quantitativa dos programas escolhidos com a totalidade de programas oferecidos, para ver qual a porcentagem de programas com os quais interagem.

Nesta pesquisa, devem-se distinguir com clareza os dois planos envolvidos: o específico dos programas vistos pelas crianças e o geral da oferta programática disponível. As crianças irão descobrindo o tipo de programação dominante que vêem, mas, ao mesmo tempo, os tipos dominantes de programas em cada canal e, em seguida, em cada horário. Para isso, deverão recorrer às várias cores para colorir cada fase descrita acima. Quando se colorir os grupos de programas e horários de transmissão, saltarão aos olhos das crianças os blocos onde está classificada a progra-

Resumo: $O$ artigo aborda a questão do protagonismo da TV na vida cotidiana das sociedades contemporâneas e, principalmente, na vida da criança. O autor, diante disso, apresenta uma proposta pedagógica que, a partir de exercícios lúdicos, orienta o desenvolvimento cognoscitivo do público infantil. Ele descreve cada passo desses exercícios, mostrando como os professores podem trabalhar com seus alunos uma nova maneira de ver TV. A idéia é que haja uma interação mais produtiva dos telespectadores com a TV; uma interação que possibilite ao público uma posição cada vez mais livre, autônoma e crítica diante da TV.

Palavras-chave:TV, telespectadores, teleaudiência, pedagogia, crianças mação. As cores têm a finalidade precípua de tornar evidente a classificação.

Ao discutir as diversas classificações, procura-se fazer com que as crianças tenham a base para explorar os motivos de suas preferências programáticas o que, por sua vez, é a base para uma seleção mais consciente. Isto significa que as crianças se prepararão para constituir-se medidores da sua própria teleaudiência.

Os exercícios referidos anteriormente pretendem ilustrar o tipo de exploração possível frente à educação dos telespectadores, assim como o tipo de conhecimento possível, com relação à teleaudiência. Os exercícios não são exclusivos, mas sim processos abertos que podem ser continuados, modificados e adequados às condições e expectativas concretas de cada grupo de participantes. Podem-se repetir quantas vezes for necessário e podem-se realizar isoladamente ou de forma interligada.

Abstract. The article touches on the matter of TV protagonism on day-to-day life in contemporaneous society, particularly on the life of the children. The author, confronted with this, presents a teaching proposal that, based on ludic exercises, orients the child's public cognoscitive development. $\mathrm{He}$ describes each step of these exercises, showing how teachers can work with their students on a new way to watch TV. The idea is that there be a more productive interaction between viewers and TV; an interaction that allows the public to have a freer, more autonomous and more critical position in relation to TV.

Key words: TV, viewers, tele-audience, teaching, children 